\title{
KEARIFAN LOKAL KABANTI UNTUK MASYARAKAT BUTON (PENELITIAN ANALISIS KONTEN)
}

\author{
Sahlan \\ Universitas Halu Oleo \\ Email: sahlan89@yahoo.com
}

\begin{abstract}
The aims of this research is to describe the local wisdom in Kabanti for people of Buton. In order to describe the matter, the researcher Ude through five informan and three Kabanties written by Haji Abdulu Ganiyyu as the source of data. The data were collected using observation, interview, and documentation techniques. The data validity were varified using triangulation method through theoretical and logical information. The data were analyzed using content analysis, hermeneutic and semiotic. The research conclude the general illustration of kabanti looks like Poe that apart of them be sang by the people of Buton. Kabanti containing the values of local wisdom in for aspects. The first aspect, the live vision of the people of Buton is based on religous value namenly the relation of human being with Allah SWT, the relation of human being with human being, and the relation of human being with the nature. The Second, norma or law aspect of the people of Buton have values; Obey to regulation, fair attitude, to take the honorable to the human being and always Control themselves. The Third aspect, social aspect of the people of Buton have the values; Love, Care, take the honorable Beach other and respect. The Fourth, the culture aspect of the people of Buton have the values, sincerity, tolerance, togetherness all. Therefore, local wisdom in kabanto of Buton society has implications for the insight Development and student implementation in learning Education character.
\end{abstract}

Key Words: local wisdom, character, culture, norm, value.

\begin{abstract}
Abstrak
Tujuan penelitian ini adalah untuk mendeskripsikan kearifan lokal Kabanti untuk masyarakat Buton. Untuk mendeskripsikan materi ini, peneliti Ude melalui 5 informan dan 3 orang penulis Kabanti oleh Haji ABdulu Ganiyyu sebagai sumber data. Data dikumpulkan menggunakan observasi, wawancara, dan teknik dokumentasi. data validitas menggunakan metode triangulasi melalui teori dan informasi logis. Data dianalisis menggunakan analisis konten, hermeneutic and semiotic. Peneliti menyimpulkan ilustrasi umum dari Kabanti seperti puisi bahwa bagian mereka adalah lagu masyarakat Buton. Kabanti yang berisi nilainilai kearifan lokal dalam beberapa aspek. Aspek pertama, visi kehidupan masyarakat Buton didasarkan nilai religius yang mengutamakan hubungan manusia dengan Allah SWT, hubungan manusia dengan manusia, dan hubungan manusia dengan alam. Kedua, norma atau aspek hukum masyarakat Buton memiliki nilai yaitu: patuh pada peraturan, sikap adil, menghormati manusia dan selalu mengkontrol diri mereka. Aspek ketiga, aspek sosial masyarakat Buton memiliki beberapa nilai yaitu: Cinta, peduli dan saling menghormati. Keempat, aspek budaya masyarakat Buton memiliki beberapa nilai, kasih sayang, toleransi, dan kebersamaan. Oleh karena itu kearifan lokal Kabanti masyarakat Buton memiliki implikasi untuk perkembangan pengetahuan dan penerapan pendidikan karakter untuk siswa
\end{abstract}

Kata kunci: kearifan lokal, karakter, budaya, norma, nilai 


\section{PENDAhULUAN}

Puisi sebagai salah satu bentuk sastra merupakan hasil pemikiran manusia yang konkret dan artistik dengan bahasa perasaan (emosional). Pradopo (2000: 7) menyimpulkan adanya tiga unsur pokok dalam puisi, yaitu pertama pemikiran atau ide, kedua bentuk atau struktur, dan ketiga kesan atau pesan yang ingin disampaikan. Oleh karena itu, Kabanti sebagai bentuk puisi daerah yang sarat dengan; nilai-nilai dan norma, serta falsafah hidup yang dalam tulisan ini disebut sebagai kearifan lokal.

Kearifan lokal merupakan gagasan pengetahuan dari suatu komunitas masyarakat yang digunakan dari generasi ke generasi selanjutnya untuk bertahan hidup dalam suatu lingkungan kolektif (Gunawan, 2003: 6). Kabanti yang menjadi bahan kajian ini dapat mengandung aspek-aspek kearifan lokal, karena kabanti merupakan karya sastra masyarakat Buton yang berbentuk puisi. Masuknya ajaran Islam di Buton mengubah kerajaan menjadi Kesultanan Buton (1538 M) turut mewarnai perkembangan kesusastraan masyarakat Buton, terutama Kabanti. Pada awal Kesultanan Buton kesusastraan hanya diwariskan secara turuntemurun, karena saat itu belum mengenal aksara (Saidi, 2005:2). Kabanti merupakan bagian dari wujud kearifan lokal. Kearifan lokal merupakan usaha yang dilakukan oleh manusia untuk memberikan makna secara manusiawi untuk menata kehidupan mereka yang manusiawi pula yakni dalam wujud nilai-nilai luhur.

Fakta di lapangan menunjukkan bahwa nilai-nilai luhur kehidupan masyarakat kita telah mulai luntur. Banyak nilai-nilai kearifan lokal mulai diabaikan oleh masyarakat lokal terutama generasi muda sebagai dampak dari era globalisasi. Lunturnya, nilai-nilai luhur masyarakat terkontaminasi budaya-buaya asing yang berbeda dengan nilai-nilai kehidupan masyarakat kita. Saat ini para pelajar banyak terlibat dalam berbagai perilaku negatif seperti tawuran, pornografi, dan bentuk kriminal lainnya yang berbeda dengan nilai-nilai luhur bangsa Indonesia. Dalam konteks ini nilai diartikan sebagai patokan normatif yang mempengaruhi manusia untuk menentukan pilihannya di antara cara-cara berpikir, bertindak, dan berprilaku.

Oleh karena itu, perlu ada upaya penyaringan (filter) yang salah satunya adalah menggali kearifan lokal dalam sastra daerah seperti kabanti pada masyarakat Buton. Mengenal serta memahmi kearifan lokal dapat menjadi landasan berpijak dalam hidup di tengah-tengah masyarakat yang multietnis. Kearifan lokal itu juga dapat menjadi bahan-bahan pembelajaran di sekolah agar generasi memahami nilai-nilai kehidupan bermasyarakat dan bernegara. Nilai-nilai kehidupan yang dibangun melalui sarana pembelajaran kearifan lokal dengan sendirinya akan menjadi landasan kearifan nasional, sehingga terbentuk suatu generasi yang memiliki ketahanan karakter yang kokoh dari berbagai pengaruh budaya lain terutama budaya asing.

Telaah tentang nilai-nilai kearifan lokal, saat ini dipandang sangat relevan dengan rintisan penyelenggaraan pendidikan karakter. Menurut Zubaedi (2011: 72) mulai tahun 2011 semua satuan pendidikan di Indonesia mulai melaksanakan pendidikan karakter. Tujuannya adalah mengembangkan karakter peserta didik yang berlandas pada nilai-nilai luhur bangsa.

Pertimbangan dipilihnya kabanti karya sastra masyarakat Buton sebagai bahan kajian dalam penelitian ini. Pertimbangan lain adalah (a) kabanti merupakan warisan yang telah ada sejak Kesultanan Buton, (b) para seniman kabanti secara umum dari para pejabat Kesultanan Buton, (c) kabanti ditulis dalam aksara Arab yang dikenal dengan Buri Wolio. 


\section{A. Kabanti Bentuk Puisi Masyarakat Buton}

Wujud puisi adalah bahasa padat (sedikit kata-kata, tetapi mengandung banyak makna). Keindahan struktur (rima, ritme, musikalitas) dalam bahasa yang digunakan sangat diperhatikan. Makna yang terkandung dalam puisi dapat berupa pikiran, perasaan, pendapat, kritikan, dan lain-lain. Pada masyarakat Buton sebagai turunan dari masyarakat kesultanan kabanti dipandang sebagai bentuk puisi yang menyerupai syair. Puisi yang dimiliki oleh masyarakat Buton memiliki kemiripan dengan bentuk-bentuk syair di berbagai daerah (Zuhdi, 2010: 30). Puisi Kabanti berkembang pesat setelah masuknya agama islam di Kerajaan Buton. Masuknya ajaran agama islam sanggup mengubah status kerajaan Buton menjadi kerajaan Islam (kesultanan) yang turut pula mewarnai perkembangan sastra di Buton. Dari segi bentuknya, kesusastraan jenis Kabanti dapat dikelompokkan menjadi dua bagian, yaitu pantun dan syair. Kabanti yang tergolong kelompok pantun pada umumnya berbentuk pendek-pendek, kadang-kadang terdiri atas lampiran dan isi, dan kadang pula hanya berupa isi saja. Syair bentuknya panjang-panjang, dan merupakan hasil pengolahan secara bebas dari kesusastraan bentuk prosa.

\section{B. Kearifan Lokal}

Kearifan lokal merupakan inti pengetahuan suatu masyarakat dan sebagai pengetahuan yang menyeimbangkan kepentingan bersama. Stenberg (1993: 317320) menyatakan bahwa kearifan merupakan suatu konstruk yang multidimensional, yakni perpaduan dari elemen-elemen kognitif, afektif, dan konatif. Jadi, kearifan berkembang berdasarkan keseimbangan kognisi, konsesi, dan afeksi. Proses kearifan tersebut menghasilkan produk-produk arif, seperti perencaaan, keputusan, dan nasihat yang diterapkan dalam kehidupan masyarakat. Masyarakat multikultur mempunyai dampak negatif dan positif. Pada satu sisi, tradisi majemuk dalam masyarakat multikultur selalu terjadi konflik budaya, dan pada sisi yang lain tradisi yang berbeda dapat saling melengkapi.

Rahyono (2009: 8) merilis pandangan tentang local genius bahwa lokal genius merupakan kecerdasan manusia yang dimiliki oleh sekelompok etnis dari masyarakat yang diperoleh melalui pengalaman hidupnya dan terwujud dalam ciri-ciri budaya yang dimilikinya. Kecerdasan yang dimiliki oleh masyarakat bersangkutan dalam menghasilkan budaya berdasarkan pengalaman hidupnya. Pembelajaran kearifan lokal menjadi penting karena sekarang ini dunia pendidikan termasuk di Indonesia sedang mewacanakan pendidikan multikultural. Pendidikan multikultural itu sendiri memiliki banyak makna (Supriyoko, 2005: 15-16). Kearifan lokal harus ditanamkan secara dini kepada siswa. Untuk itu, kearifan lokal hendaknya menjadi bahan pembelajaran di sekolah. Materi kearifan lokal dapat reintegrasi dalam Pembelajaran Bahasa dan Sastra Indonesia dan pembelajaran Muatan Lokal.

\section{Pendidikan Karakter}

David Elkind dan Freddy Sweet yang dikutip oleh Zubaedi (2011: 15) menyatakan bahwa pendidikan karakter adalah usaha secara sengaja untuk membantu peserta didik agar dapat memahami dan menerapkan nilainilai etika. Hal ini berarti untuk mendukung perkembangan karakter peserta didik, harus melibatkan seluruh komponen sekolah baik dari aspek isi kurikulum, proses pembelajaran, aktivitas ko-kurikuler, mata pelajaran, dan komponen sekolah. Muatanmuatan dalam pendidikan karakter sangat relevan dengan nilai-nilai luhur bangsa 
Indonesia. Nilai-nilai luhur tersebut banyak tercermin pada karya-karya sastra daerah yang tersebar di nusantara, termasuk sastra daerah bentuk puisi Kabanti masyarakat Buton. Khusus pada kabanti puisi masyarakat Buton telah dijadikan sebagai petunjuk dan pedoman masyarakat dalam beraktivitas baik untuk kepentingan kehidupan dunia maupun untuk kepentingan kehidupan di akhirat.

Oleh karena itu, pendidikan karakter dapat berkolaborasi dengan kearifan lokal dalam menanamkan nilai-nilai luhur yang dipandang relevan dengan pilar-pilar dalam pendidikan karakter yang telah dirancang dalam pembelajaran di sekolah. Hal ini dimaksudkan untuk dapat mempercepat pemahaman dan penerapan peserta didik tentang nilai-nilai kehidupan yang diperkenalkan oleh guru. Begitu pula bagi guru, akan lebih memudahkan memberikan contoh-contoh melalui kehidupan seharihari. Penelitian ini bertujuan untuk menemukan bentuk-bentuk kearifan lokal dalam kabanti puisi masyarakat Buton.

\section{METODOLOGI PENELITIAN}

Penelitian ini menggunakan metode kualitatif dengan teknik analisis isi (content analysis). Dalam penerapan teknik ini dipadukan dengan teknik telaah sastra yakni telaah hermeneutik dan semiotik. Berdasarkan tujuan itu, maka yang menjadi subtujuan dalam penelitian ini adalah sebagai berikut. (1) untuk mengungkapkan gambaran umum kabanti sebagai bentuk puisi masyarakat Buton. (2) untuk mengungkapkan bentukbentuk kearifan lokal dalam kabanti pada aspek pandangan hidup masyarakat. (3) untuk mengungkap bentuk-bentuk kearifan lokal dalam kabanti pada aspek norma masyarakat. (4) untuk mengungkap bentukbentuk kearifan lokal dalam kabanti pada aspek sosial. (5) untuk mengungkap bentukbentuk kearifan lokal dalam kabanti pada aspek budaya. (6) untuk mengungkap implikasi kearifan lokal dari kabanti terhadap nilai-nilai yang dijabarkan dalam pendidikan karakter di sekolah. Untuk mendapatkan gambaran penggunaan metode, dapat kita lihat melalui bagan berikut ini.

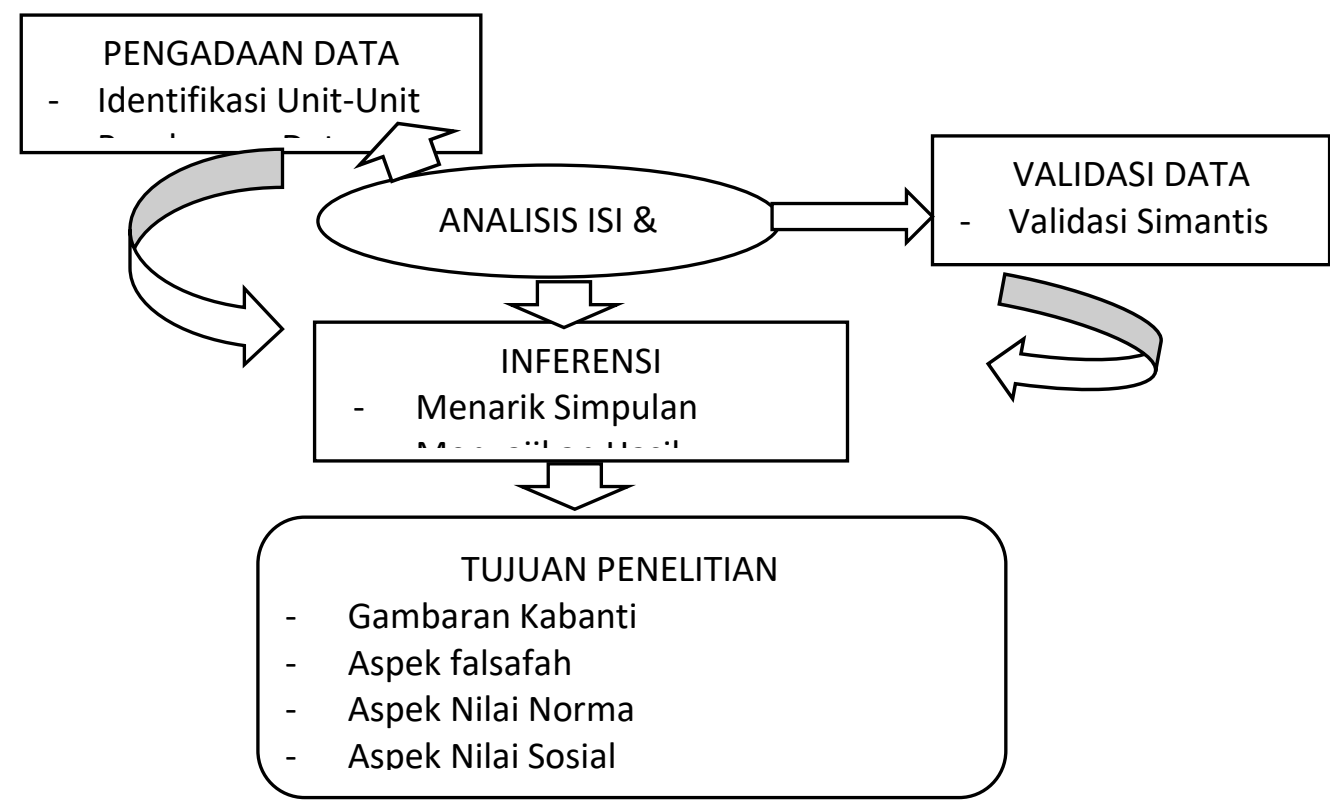

Bagan 1. Gambar Pengguna Metode 
Penelitian ini dilaksanakan di Kota Bau-bau dan Kabupaten Buton Sulawesi Tenggara. Kedua tempat itu dipandang representatif dibandingkan wilayah-wilayah lainnya dalam kekuasaan Kesultanan Buton. Untuk tempat pengambilan data ditetapkan tiga kecamatan, yaitu Kecamatan Murhum di Kota Bau-Bau, Kecamatan Pasar Wajo Kabupaten Buton, dan Kecamatan Lakudo Kabupaten Buton. Penelitian ini dilaksanakan selama 14 bulan, yakni mulai bulan November 2010 sampai dengan Desember 2011. Sumber data yang digunakan adalah tiga naskah kabanti yang telah dikarang oleh Haji Abdulu Ganiyyu, yaitu Paiyasa Mainawa (PM), Kulipopo Mainawa (KM), dan Ajonga Inda Malusa (AIM).

Prosedur penelitian dilakukan melalui tiga langkah, yaitu pengadaan data, validasi data, dan inferensi atau analisis data. Penelitian ini menggunakan tiga teknik pengumpulan data. Ketika teknik tersebut meliputi; (a) wawancara yakni untuk mendapatkan data kearifan lokal masyarakat Buton, (b) Pengamatan untuk mendapatkan data tentang kehidupan masyarakat Buton pada masa kini, dan (c) dokumentasi untuk mendapatkan bentuk-bentuk kearifan lokal dalam kabanti sebagai bentuk puisi masyarakat Buton. Penelitian ini menggunakan teknik content analysis dan teknik telaah hermeneutik. Untuk keabsahan data digunakan teknik triangulasi baik triangulasi teoretis maupun triangulasi logis.

\section{HASIL DAN PEMBAHASAN}

Penelitian temuan ini mencakup enam hal. (a) Gambaran umum kabanti masyarakat Buton. (b) Nilai-nilai kearifan lokal kabanti pada aspek pandangan hidup. (c) nilai-nilai kearifan lokal kabanti pada aspek norma. (d) Nilai-nilai kearifan lokal kabanti pada aspek sosial. (e) Nilai-nilai kearifan lokal kabanti pada aspek budaya. (f) Implikasi dan implementasi nilai-nilai kearifan lokal terhadap pendidikan karakter.

Kabanti merupakan salah satu bentuk karya sastra yang diwarisi oleh masyarakat Buton secara turun-temurun sejak zaman Kesultanan Buton pada abad XVII. Gambaran umum kabanti puisi masyarakat Buton cenderung sama dengan puisi pada umumnya yaitu menggunakan kata-kata yang padat. Dari segi bentuknya, kesusas-traan jenis Kabanti dapat dikelompokkan menjadi dua bagian, yaitu pantun dan syair. Kabanti yang tergolong kelompok pantun pada umumnya bentuknya pendek-pendek, kadang-kadang terdiri atas sampiran dan isi, dan kadang-kadang pula hanya berupa isi saja. Syair bentuknya panjang-panjang, dan merupakan hasil pengolahan secara bebas dari kesusastraan bentuk prosa. Kabanti sebagai bentuk puisi masyarakat Buton sekarang ini banyak berbentuk naskah yang ditulis tangan oleh pengarah dengan menggunakan aksara Wolio (yang diambil dari aksara Arab). Jika ditinjau dari segi Kosta kata yang digunakan dalam kesusastraan jenis Kabanti tampaknya tidak secara etimologi menyerap Kosta kata dari bahasa Arab. Kata-kata bahasa Wolio telah mengalami proses adaptasi fonologis ke dalam bahasa Wolio yang berciri bahas vokalis. Oleh karena itu, kata-katanya dianggap sebagai bagian dari Kosa kata bahasa Wolio yang kemudian dikenal dengan istilah Kabanti Oni Wolio 'Puisi bahasa Wolio'.

Secara umum isi (kandungan) kabanti bentuk puisi masyarakat Buton menguraikan tentang hidup dan kehidupan manusia. Isi kabanti tersebut meliputi aspek keimanan, pandangan hidup, budi pekerti, norma, pemerintahan, pendidikan, dan budaya. Oleh karena itu masyarakat memandangknya sebagai pedoman dan nasihat yang sering dibawakan dalam bentuk nyanyian. 
Berdasarkan hasil analisis data dapat disimpulkan bahwa ketiga buah kabanti tersebut berdasarkan isi kandungannya menyerupai bentuk puisi yang tergolong syair, akan tetapi dari segi bentuknya berbeda dengan syair. Oleh karena itu, kabanti masyarakat Buton ini dikategorikan sebagai bentuk puisi yang dikarang untuk menjadi tuntunan hidup dan kehidupan bagi masyarakat.

Ketiga buah kabanti yang dikaji memiliki tema yang berbeda-beda, meskipun dasar jabarannya tentang religius dan kehidupan manusia. Kabanti Paiyasa Mainawa lebih menekankan pada tema religius. Kabanti Kalipopo Mainawa pengarang menguraikan tema tentang kejadian alam sebagai tanda kekuasaan Allah SWT. Pada Kabanti Ajonga Inda Malusa banyak mengungkapkan hal-hal yang berkaitan dengan kehidupan dalam masyarakat. Dari gambaran isi dan kandungan ketiga kabanti tersebut dapat kita menyimpulkan bahwa kabanti pada dasarnya berisi ajaran tentang kehidupan yang ideal. Hal ini dimaksudkan agar masyarakat Buton memahami eksistensi dirinya baik sebagai pemerintah maupun sebagai masyarakat biasa. Isi ketiga kabanti tersebut maka tercakup aspek-aspek; (a) religius, (b) pandangan hidup, (c) budi pekerti, (d) norma dan hukum, (e) kebudayaan, (f) pemerintahan, (g) pengetahuan, (h) kegiatan sosial, (i) adat-istiadat, (j) abdi terhadap pemerintah, dan (k) bela negara. Jadi, ketiga kabanti yang dianalisis mengandung isi semua aspek kehidupan bernegara dan bermasyarakat.

Nilai-nilai kearifan lokal pada aspek pandangan hidup masyarakat Buton berlandas pada syariat Islam yang meliputi pandangan hidup tentang hubungan manusia dengan Allah, hubungan manusia dengan manusia, dan hubungan manusia dengan alam. Hubungan manusia dengan Allah diletakkan sebagai landasan utama, hubungan antar manusia tercermin pada falsafah bhinci-bhinciki kuli, dan hubungan manusia dengan alam mengutamakan keselamatan negeri. Hal tersebut terungkap pada semboyan masyarakat, "bholimo arata sumanamo karo, bholimo karo sumanamo Lipu, bolimo Liu sumanamo agama" yang artinya "Tidak perlu harta yang penting diri selamat, tidak perlu diri yang penting negeri tetap utuh, tidak perlu negeri yang penting agama ditegakkan".

Nilai-nilai kearifan lokal aspek norma juga berdasar pada syariat Islam. Dalam penerapannya terjabar pada tiga pilar norma, yaitu norma hukum, norma sosial, dan norma adat. Ketiga wujud norma tersebut memiliki peranan penting dalam tata kehidupan masyarakat dan pemerintah-an. Normanorma itu menjadi standar atau acuan untuk berperilaku, bersikap, serta berpikir yang penerapannya secara adil bagi semua kalangan masyarakat. Oleh karena itu pelanggaran norma lebih terkendali karena setiap pelanggaran akan dikenakan sanksi.

Nilai-nilai kearifan lokal pada aspek sosial terkandung nilai-nilai luhur yang berlandaskan syariat Islam. Artinya, jabaran di dalamnya mencakup budi pekerti atau akhlakul jariah yang dalam kabanti diberikan istilah budiman. Pada konteks ini budimani mempunyai beberapa indikator yang merujuk pada falsafah masyarakat Buton yakni 'bhinci-bhinciki kuli'. Falsafah ini tertuang dalam empat prinsip, yaitu (a) sesama manusia harus saling menghormati, (b) sesama manusia harus saling peduli, (c) sesama manusia harus saling menyayangi, dan (d) sesama manusia harus selalu saling memuliakan. Orang yang memiliki perilaku tersebut masyarakat Buton menjuluki dengan budiman (akhlak mulia). Prinsip- prinsip hidup inilah yang membentuk masyarakat menjadi hidup damai, bekerja sama, tolongmenolong, berempati, walaupun masyarakat Buton termasuk masyarakat multietnis. 
Nilai-nilai kearifan lokal pada aspek budaya mencerminkan budaya islami. Budaya Posuo misalnya, merupakan pengislaman remaja wanita (kabua-bua) menjadi dewasa (kalambe). Mereka diajarkan tentang Islam, menghargai orang tua, eksistensi wanita sebagai istri. Implementasinya pada budaya pobaisa yakni perkawinan yang dilakukan secara adat dengan rambu-rambu Islam. Budaya haroa dilaksanakan untuk berserah diri sambil berdoa kepada Allah SWT untuk keselamatan. Pada tradisi Palade-kandea menyuguhkan makanan kepada orang lain sebagai tanda syukur atas nikmat Allah. Tradisi pohamba-hamba membantu orang lain secara suka rela penyelesaian pekerjaan dari anggota masyarakat.

Temuan-temuan dalam analisis kabanti sebagai bentuk kearifan lokal masyarakat Buton dapat berimplikasi langsung terhadap pengembangan dan pembelajaran nilai-nilai luhur dalam pendidikan karakter di sekolah. Hal ini sangat dimungkinkan oleh pola pendidikan sekarang ini yang menekankan pada konteks dan penerapan. Kehidupan sehari-hari yang dialami oleh siswa di rumah atau pada masyarakat mengambil peran yang sangat besar untuk penerapan nilai-nilai karakter yang dipelajari di sekolah. Oleh karena itu peran orang tua dan masyarakat dalam keberhasilan pendidikan karakter sangat diharapkan, sehingga perlu adanya sinergi antara sekolah, orang tua, dan masyarakat. Asumsi tersebut berangkat dari kerangka pendidikan karakter seperti yang diungkapkan Zubaedi (2011) pendidikan karakter pada dasarnya mencakup tiga aspek dasar yaitu: pengembangan substansi, proses pembelajaran, serta penciptaan suasana lingkungan yang menggugah atau mendorong seseorang untuk mengembangkan kebiasaan yang baik dalam kehidupan sehari-hari.
Hal yang demikian, searah dengan kearifan lokal masyarakat Buton yakni, bhinci-bhinci ki kuli yang berarti 'mencubit diri sendiri'. Oleh karena itu pada konteks masyarakat Buton pendidikan karakter hendaknya siswa banyak diarahkan melalui pengamatan langsung dalam kehidupan masyarakat sehari-hari. Hal tersebut sejalan dengan pembelajaran kontekstual yang lebih menekankan pada suasana lingkungan pembelajaran pada kegiatan belajar mengajar yang dikembangkan oleh guru di sekolah.

\section{PENUTUP}

\section{A. Simpulan}

Gambaran umum kabanti puisi masyarakat Buton memiliki bentuk yang panjang sebagaimana bentuk-bentuk syair pada puisi lama. Perbedaannya dengan syair kabanti adalah kabanti tidak menerapkan bentuk-bentuk persajakan secara ketat. Kabanti digunakan sebagai hiburan pada acara-acara adat dalam masyarakat. Sementara itu isi kabanti berupa anjuran tentang kebaikan yang di dalamnya mengurai masalah iman kepada Allah, budi pekerti, norma/hukum, hubungan sosial, pemerintahan, pendidikan, dan adat-istiadat.

Kearifan lokal masyarakat pada aspek norma terdapat tiga pilar norma yaitu: norma hukum, norma sosial, dan norma adatistiadat. Masing-masing norma memiliki peranan penting dalam tata kehidupan masyarakat, karena dapat menjadi pedoman berprilaku dap bersikap. Kearifan lokal masyarakat Buton pada aspek sosial terkandung nilai-nilai luhur yang sarat dengan nuansa Islam. Hal ini terangkum dalam, 'bhinci-bhinci kuli' yang memuat pomaa-maasiaka, pomae-maeka, popiapiara, dan poangka-angkataka. Produkproduk budaya yang diterapkan dalam kehidupan masyarakat berdasar pada syariat Islam. Hal ini tentu tidak lepas dari peran 
sistem pemerintahan di masa lalu yang berbentuk kesultanan.

Pembelajaran pendidikan karakter yang saat ini menjadi target kurikulum di sekolah menjadi wahana untuk dijadikan sebagai nilai-nilai luhur masyarakat yang perlu dikemas, diajarkan oleh guru melalui pembelajaran karakter. Jika langkah ini dilakukan maka budaya-budaya lokal tetap akan lestari, bahkan dapat menjadi penangkal (filter) dari pengaruh budaya luar terutama budaya barat.

\section{DAFTAR PUSTAKA}

Abror, A. R. (2009). Pantun Melayu: Titik Temu Islam dan Budaya Lokal Nusantara. Yogyakarta: LKIS Printing Cemerlang.

Alisjahbana, S. T. (2009). Puisi Lama. Jakarta: Dian Rakyat.

Gunawan, R. (2003). Kearifan Lokal dalam Tradisi Lisan. Jakarta: Pusat Bahasa.

Ong, W. J. (2007). Orality and Literacy: The Technologizing of the Word. London and New York: Routledge.

Pradopo, R. D. (2000). Pengkajian Puisi Analisis Strata Norma dan Struktural dan Semiotik. Yogyakarta: Gajah Mada University Press.

Rahyono, F. X. (2009). Kearifan Budaya dalam Kata. Jakarta: Wadatama Widya Sastra.

Saidi, E. A. M. (2005). Naskah Kesultanan Buton sebagai Sumber Kekayaan Dunia: Bau-bau: Simponsium Pernaskahan Nusantara.
Supriyoko, Ki Ed. (2005). Pendidikan Multikultural dan Revitalisasi Hukum Adat: dalam Perspektif Sejarah. Jakarta: Karya Agung.

Zubaedi. (2011). Desain Pendidikan Karakter: Konsepsi dan Aplikasinya dalam Lembaga Pendidikan. Jakarta: Kencana Prenada Group. 